\title{
Can the Presence of Atrial Fibrillation Influences the Levels of Heart Failure - Specific Biomarkers in Overweight and Obese Patients with Heart Failure?
}

\author{
ALEXANDRA DADARLAT ${ }^{1}$, DANA POP1,2*, ANCA DANIELA FARCAS ${ }^{1,3}$, DUMITRU ZDRENGHEA $^{1,2}$, GYORGY BODIZS ${ }^{2}$, \\ RALUCA TOMOAIA ${ }^{1}$, DIANA GURZU ${ }^{1}$, SILVANA SUSCA-HOJ DA ${ }^{1}$, FLORINA FRINGU ${ }^{1}$, ANCA DANA BUZOIANU 4 \\ ${ }^{1}$ Iuliu Hatieganu University of Medicine and Pharmacy, Cluj-Napoca, Victor Babes Str., 400012, Cluj Napoca, Romania \\ ${ }^{2}$ Clinical Rehabilitation Hospital, 46-50 Viilor Str., 400347, Cluj-Napoca, Romania \\ ${ }^{3}$ Emergency Clinical County Hospital, Cardiology Department, 3-5 Clinicilor Str, 400006, Cluj Napoca, Romania \\ ${ }^{4}$ Iuliu Hatieganu University of Medicine and Pharmacy, Cluj-Napoca, Romania, Dept. of Pharmacology, Toxicology and Clinical \\ Pharmacology
}

\begin{abstract}
Heart failure continues to be a major worldwide medical issue, associated with high morbidityand mortality. The need for ideal biomarkers to aid the diagnosis and prognosis in certain situations, such as obesity or atrial fibrillation is still ongoing. Obese patients are commonly hyperleptinemic. The aim of the study is to assess the role of several biomarkers in overweight and obese patients diagnosed with heartfailure, depending on the presence or absence of atrial fibrillation and also their relationship with leptin. The study included 88 overweight and obese patients, with a body mass index (BMI) $\geq 25 \mathrm{~kg} / \mathrm{m}^{2}$, admitted for worsening heart failure. Of these, $52.2 \%$ had atrial fibrillation. Dosage of NT-proBNP was performed using the chemiluminescence method. MR-proANP, galectin-3 and leptin were dosed using the ELISA method. A value of $P<0.05$ was defined as statistically significant. The values of natriuretic peptides NT-proBNP and $M R$-proANP were significantly increased. Only NT-proBNP was significantlyinfluenced by renal function. No statistically significant correlation was found between heartfailure-specific biomarkers and leptin secretion. There were no significant differences in the biomarkers levels between the 2 groups of patients. No statistically significant correlation was found between heart failure-specific biomarkers and leptin secretion. Obese patients with heart failure had significantly increased values of all the studied parameters, but the presence of atrial fibrillation did not influence their levels. High leptin levels were not directly correlated with the levels of heart failure-specific biomarkers.
\end{abstract}

Keywords: heart failure, biomarkers, obesity, atrial fibrillation

Since natriuretic peptides (BNP and NT-proBNP) gained approval for clinical use as biomarkers of heart failure in 2000, they have become extremely useful in making diagnosis, assessing severity, risk of acute events, and guiding therapy of heart failure. In addition to these classical, routinely used biomarkers recommended by current guidelines for the diagnosis and treatment of heart failure [1], other biomarkers with a role in stratifying risk or guiding treatment of heart failure have been described.

BNP (B-type natriuretic peptide) and NT-proBNP (amino-terminal pro-brain natriuretic peptide) are secreted by the myocardium directly into systemic circulation as a result of an increase in parietal stress under volume or pressure overload conditions [1, 2]. The initial product of BNP is pre-proBNP, which is rapidly transformed into proBNP by removal of 26 amino acids. Subsequently, this is cleaved by proteolytic enzymes into NT-proBNP and BNP, but only the latter is biologically active. Although clearance of both occurs in high blood flow-dependent organs such as the kidney, the half-life of NT-proBNP is much longer than that of BNP (120 min vs. 20 min) [2]. Increased serum BNP or NT-proBNP concentrations are heartfailure severity markers [1]. Among heart failure patients, a special category is that of obese patients. These have certain particularities, including a frequently normal ejection fraction (preserved ejection fraction) and lower levels of cardiac natriuretic peptides [1, 2]. This is why the cut-off values recommended by natriuretic peptide guidelines for heart failure diagnosis can induce false-negative results in obese patients. In this context, identifying other more sensitive biomarkers might contribute to an increase in diagnostic sensitivity and more precise guiding of treatment in this category of patients.

MR-proANP is a promising biomarker for the correct diagnosis of heart failure, much more stable than NTproANP, which has demonstrated its non-inferiority to BNP in clinical practice, in the diagnosis of acute heart failure, improving at the same time the diagnosis of patients with upper limit values of BNP, as well as obese patients [1, 3]. The cut-off value of this cardiac peptide recommended by current European heart failure guidelines to exclude heart failure is $120 \mathrm{pmol} / \mathrm{L}$ [1].

However, it should not be forgotten that tissue damage in heartfailure induces a significant inflammatory response with the release of pro-inflammatory cytokines and an increase in the number of cell adhesion molecules [4]. Another important biomarker of inflammatory response in heart failure is galectin-3 (Gal-3), a lectin member of the galectin family [2]. Gal-3 expression is increased in activated macrophages, as well as in the heart through proteins and other molecules. Gal-3 plays an important role in pathological cardiac remodeling, particularly by stimulating fibroblast proliferation and collagen deposition. Gal-3 concentrations are increased in patients with heart failure, including those with preserved ejection fraction. This is why Gal-3 may have a role in risk stratification: Gal3 values $>17.8 \mathrm{ng} / \mathrm{mL}$ are associated with low risk, Gal-3 values between 17.9 and $25.9 \mathrm{ng} / \mathrm{mL}$ show moderate risk, 
and values higher than $25.9 \mathrm{ng} / \mathrm{mL}$ indicate high risk [2] However, so far it is not known whether these values should be adjusted depending on comorbidities. There are also data showing the implication of Gal-3 in the development of obesity, as a modulator of adipogenesis. It seems that Gal-3 concentrations are higher in obese patients, but the links between galectin-3, obesity and heart failure with preserved ejection fraction are still incompletely understood [5]

Also, it is well-known thatobese patients have excessive secretion of leptin, an adipokine with pro-inflammatory and atherogenic properties produced by adipocytes [6] .

Many obese patients are diagnosed with cardiac arrhythmia, especially atrial fibrillation, which worsens their prognosis, while obese patients with heart failure generally have a more favorable prognosis compared to normal weight or cachectic patients $[7,8]$.

Determining a greater number of biomarkers in obese patients with heartfailure can provide new data, useful for a more accurate characterization and stratification of risk.

In this context, the present study aimed to assess the role that the biomarkers described above can play in overweight and obese patients diagnosed with heartfailure, depending on the presence or absence of atrial fibrillation. We also aimed to evaluate possible correlations betw een leptin levels and these biomarkers of heart failure (NTproBNP, Gal-3, MR-proANP).

\section{Experimental part}

\section{Subjects}

The study included 88 overweight and obese patients, admitted to the Cardiology service of the Clinical Rehabilitation Hospital, for cardiac decompensation events. Based on anthropometric measurements, the body mass index (BMI) was calculated. Patients with a body mass index $(\mathrm{BMI}) \geq 25 \mathrm{~kg} / \mathrm{m}^{2}$ were included and $52.2 \%$ of them had atrial fibrillation. Heart failure was defined according to the guidelines for the diagnosis and treatment of acute and chronic heart failure, published by the European Society of Cardiology in 2016 [1]. Demographic, clinical, laboratory data and echocardiographic parameters were analyzed. Overweight and obese patients with heart failure were assigned to 2 groups depending on the presence or absence of atrial fibrillation (patients with paroxysmal, persistent or permanentatrial fibrillation were included).

\section{Evaluation of heart failure specific biomarkers}

Dosage of NT-proBNP was performed on the day of admission and its measurement was carried out using the chemiluminescence method. The cut-off value for NTproBNP was $125 \mathrm{pg} / \mathrm{ml}$. MR-proANP, galectin-3 and leptin were dosed using the ELISA method. For the determination of serum concentrations of MR-proANP, Gal-3 and leptin serum was separated by centrifugation at $1500 \mathrm{~g}$ for 10 min at a temperature of $4^{\circ} \mathrm{C}$, then was transferred to $1 \mathrm{~mL}$ cryotubes and stored at a temperature of $-70^{\circ} \mathrm{C}$ for subsequent analysis.

For the quantitative determination of human midregional pro-ANP (MR-proANP) we used a quantitative sandwich enzyme immunoassay technique. Microplates were pre-coated with an antibody specific for MR-proANP. During the test standards and samples are pipetted into the wells and any MR-proANP present is bound by the immobilized antibody. After removing any unbound substances, a biotin conjugated antibody specific for MRproANP is added to the wells. After washing avidin conjugated Horseradish Peroxidase (HRP) is added.
Following a wash step a substrate solution is added and color develops in proportion to the amount of antigen bound in the initial step. The color development is stopped and the intensity of the color measured. Detection range was $39-2500 \mathrm{pmol} / \mathrm{L}$.

The ELISA test for the galectin-3 determination is based on a standard sandwich enzyme-linked immuno-sorbent assay method. A monoclonal antibody from mouse specific for Galectin -3 has been precoated onto 96 well plates. Standards and test samples are added to the wells, a biotinylated detection polyclonal antibody from goat specific for Galectine-3 is added subsequently. An incubation period is followed by washing with PBS buffer. Avidin - Biotin -Peroxidase Complex is added and unbound conjugates were washed away with PBS buffer. HRP substrate TMB is used to visualize the enzymatic reaction producing a blue color product. After adding the stop solution the color is changing to yellow. The intensity of this is proportional to the human Galectin-3 amount of the samples. Detection range: $10-100 \mathrm{ng} / \mathrm{mL}$.

The leptin serum level was detected also by a sandwich enzyme immunoassay. Standards, controls and samples are incubated in microplate wells pre-coated with polyclonal anti-human leptin antibody. After incubation and washing an HRP-conjugated anti-human leptin antibody is added to the wells and incubated with captured leptin. Following another washing step, the remaining HRP conjugate is allowed to react with the substrate solution (TMB) The reaction is stopped by addition of acidic solution and absorbance of the resulting yellow product is measured. The absorbance is proportional to the concentration of leptin. Detection cut-off value was 0.2 $\mathrm{ng} / \mathrm{mL}$. The cut-off values for MR-proANP and Gal-3 were $120 \mathrm{pmol} / \mathrm{L}$ and $17.8 \mathrm{ng} / \mathrm{mL}$, respectively.

\section{Statistical analysis}

Statistical data was obtained using the SPSS Statistics for Windows software program (version 23, IBM Corporation, Armonk, NY, USA). For continuous variables, mean values including standard deviations and median values were calculated (depending on the normality of distribution). Categorical variables are presented as numbers and percentages. Comparisons between groups were made using the ANOVA test - the Kruskal-Wallis test (for numerical data), or the Chi-square test (for nonnumerical data). Pearson and Spearman coefficients were used to describe the relationships between data. Multivariate analysis (for the evaluation of independent predictive factors for NT-proBNP, MR-proANP and galectin3) was performed taking into consideration age, sex, diabetes mellitus, arterial hypertension, left ventricular ejection fraction, atrial fibrillation, creatinine clearance, body mass index, Charlson comorbidity score. A value of $P$ $<0.05$ was defined as statistically significant.

The patients included in the study were informed about the study protocol and gave their informed consent. The study protocol was approved by the local Ethics Committee and it was conducted in accordance with the WMA International Code of Medical Ethics (Declaration of Helsinki) for experiments involving humans.

\section{Results and discussions}

The baseline characteristics of the patients are summarized in table 1.

As it can be seen, there are no significant differences except for dilated cardiomyopathy and other arrhythmias, more frequently found in patients with atrial fibrillation. Also, HDL cholesterol was lower in those patients. No 


\begin{tabular}{|c|c|c|c|}
\hline $\begin{array}{l}\text { Overweight/obese patients with heart } \\
\text { failure }\end{array}$ & With atrial fibrillation & Without atrial fibrillation & $\mathrm{p}$ \\
\hline \multicolumn{4}{|l|}{ Demographic characteristics } \\
\hline Number $(\%)$ & $46(52.2 \%)$ & $42(47.7 \%)$ & NS \\
\hline $\begin{array}{l}\text { Age } \\
\text { (mean } \pm \text { standard deviation) }\end{array}$ & $69.48 \pm 8.81$ & $69.38=10.15$ & 0.962 \\
\hline Women - Number $(\%)$ & $24(57.1 \%)$ & $21(50 \%)$ & NS \\
\hline \multicolumn{4}{|l|}{ Etiology of heart failure } \\
\hline Ischemic heart disease & $20(43.5 \%)$ & $26(56.5 \%)$ & 0.101 \\
\hline Dilated cardiomyopathy & $10(21.7 \%)$ & $5(10.9 \%)$ & 0.029 \\
\hline Valvular heart disease & $10(21.7 \%)$ & $6(13.0 \%)$ & 0.120 \\
\hline Other etiologies & $5(10.9 \%)$ & $6(13.0 \%)$ & 0.828 \\
\hline $\begin{array}{l}\text { Functional class NYHA I - II - } \\
\text { Number }(\%)\end{array}$ & $13(28.2 \%)$ & $19(45 \%)$ & \multirow{2}{*}{$\begin{array}{l}0.098 \\
\mathrm{OR}=2.1\end{array}$} \\
\hline $\begin{array}{l}\text { Functional class NYHA I - II - } \\
\text { Number }(\%)\end{array}$ & $33(71.7 \%)$ & $23(54.7 \%)$ & \\
\hline Smokers - Number (\%) & $12(26.1 \%)$ & $18(39.1 \%)$ & 0.072 \\
\hline \multicolumn{4}{|l|}{ Laboratory tests } \\
\hline 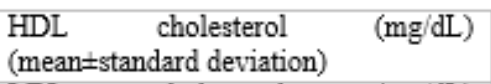 & $37.31 \pm 10.42$ & $44.14 \pm 11.46$ & 0.004 \\
\hline 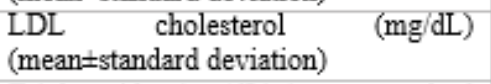 & $107.91 \pm 44.62$ & $99.43 \pm 30.53$ & 0.298 \\
\hline $\begin{array}{l}\text { Triglycerides (mg/dL) (mean } \pm \text { standard } \\
\text { deviation) }\end{array}$ & $142.55 \pm 43.80$ & $127.84 \pm 51.21$ & 0.15 \\
\hline $\begin{array}{l}\text { Glycemia }(\mathrm{mg} / \mathrm{dL}) \\
\text { (mean } \pm \text { standard deviation) }\end{array}$ & $119.71 \pm 40.25$ & $115.91 \pm 38.86$ & 0.654 \\
\hline $\begin{array}{l}\text { Creatinine }(\mathrm{mg} / \mathrm{dL}) \quad(\text { mean }=\text { standard } \\
\text { deviation) }\end{array}$ & $1.16 \pm 0.39$ & $1.09 \pm 0.46$ & 0.432 \\
\hline $\begin{array}{l}\text { NT-proBNP }(\mathrm{pg} / \mathrm{dL}) \\
\text { (mean } \pm \text { standard deviation) }\end{array}$ & $2797.17 \pm 3246.52$ & $1986.86 \pm 1811.10$ & 0.234 \\
\hline $\begin{array}{l}\text { MR-proANP (pmol/L) } \\
\text { (mean } \pm \text { standard deviation) }\end{array}$ & $519.0 \pm 766.01$ & $669.4 \pm 917.49$ & 0.422 \\
\hline $\begin{array}{l}\text { Galectin-3 }(\mathrm{ng} / \mathrm{mL}) \\
\text { (mean } \text { standard deviation) }\end{array}$ & $35.63 \pm 29.98$ & $47.75 \pm 50.33$ & 0.167 \\
\hline $\begin{array}{l}\text { Leptin (ng/mL) } \\
\text { (mean=standard deviation) }\end{array}$ & $35 \pm 32$ & $32 \pm 34$ & 0.68 \\
\hline
\end{tabular}

statistically significant differences were observed between the values of the studied serum biomarkers.

Overall, the values of natriuretic peptides NT-proBNP and MR-proANP were significantly increased. The mean value of NT-proBNP was $2410 \pm 2676 \mathrm{pg} / \mathrm{mL}$, with a median value of NT-proBNP of $1342 \mathrm{pg} / \mathrm{mL}$. The mean value of MR-proANP was $590 \pm 840 \mathrm{pmol} / \mathrm{L}$, and its median value was $246 \mathrm{pmol} / \mathrm{L}$.

The mean value of galectin- 3 was $41 \pm 41 \mathrm{ng} / \mathrm{mL}$, while its median value was $34 \mathrm{ng} / \mathrm{mL}$. Of the patients included in the study, 66 (75\%) had increased Gal-3 values (>17.8 $\mathrm{ng} / \mathrm{mL}$ ).

Of the studied biomarkers, only NT-proBNP was significantly influenced by renal function; there was an inversely proportional relationship between NT-proBNP values and creatinine clearance $(r=-0.35, p=0.01)$. Gal-3 and MR-proANP were not influenced by the alteration of renal function $(r=0.07, p=0.4 ; r=-0.02, p=0.8$, respectively).

MR-proANP and galectin-3 values did not significantly vary depending on $B M I(p=0.8, p=0.5$, respectively).

No statistically significant correlation was found between heart failure-specific biomarkers and leptin secretion in overweight and obese patients with heart
Table 1

GENERAL CHARACTERISTICS OF THE PATIENTS failure. Figure 1 presents the relationship between leptin and NT-proBNP: Spearman R correlation $=-0.101, p=0.35$, and after logarithmic transformation Pearson $R=-0.098$, $p=0.365$.

Table 2 shows that this correlation is also not significant depending on the presence or absence of atrial fibrillation. The next figure, (fig. 2), illustrates the relationship between MR-proANP and leptin.

As shown in table 3 , this correlation is also not significant depending on the presence or absence of atrial fibrillation.

Figure 3 illustrates the relationship between galectin-3 and leptin, and table 4 shows the relationship between leptinemia and galectin-3 levels in patients with and without atrial fibrillation.

Determining the serum biomarkers of heartfailure, along with clinical data and objective examination, allows a higher diagnostic accuracy for this disorder. Natriuretic peptides are the best known and studied markers of heart failure; there is current convincing evidence that they improve diagnostic performance in heart failure, including in patients with subclinical cardiac dysfunction [1]. They are particularly useful in differentiating cardiac dyspnea from non-cardiac dyspnea [1]. According to ESC guidelines 

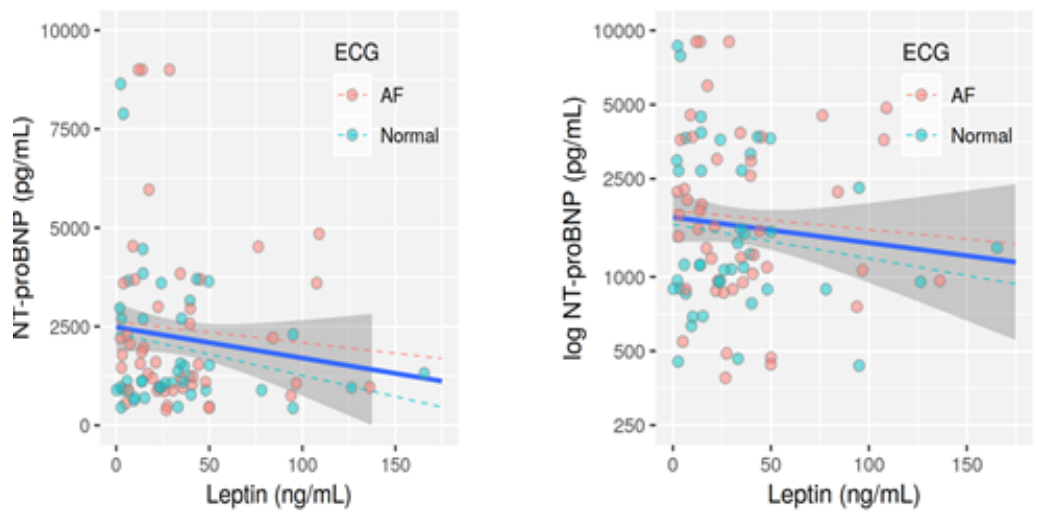

Fig. 1. Diagram illustrating the relationship between NT-proBNP and leptin secretion in overweight and obese patients with heart failure.

\begin{tabular}{|l|l|l|l|l|}
\hline ECG & $\begin{array}{l}\text { Spearman R } \\
\text { (raw data) }\end{array}$ & $\mathrm{p}$ & $\begin{array}{l}\text { Pearson R (log- } \\
\text { transformed } \\
\text { data) }\end{array}$ & $\mathrm{p}$ \\
\hline All & -0.101 & 0.35 & -0.098 & 0.365 \\
\hline AF & -0.16 & 0.287 & -0.16 & 0.287 \\
\hline Sinus rhythm & -0.037 & 0.817 & -0.037 & 0.817 \\
\hline
\end{tabular}

Table 2

THE RELATIONSHIP BETWEEN LEPTIN AND NT-PrOBNP DEPENDING ON THE PRESENCE OF ATRIAL FIBRILLATION
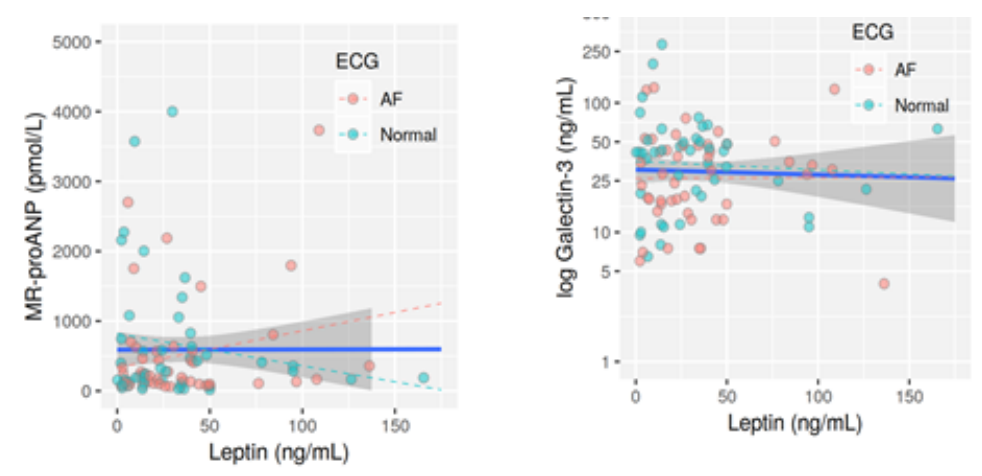

Fig. 2. Diagram illustrating the relationship between leptin and MR-proANP

\begin{tabular}{|l|l|l|l|l|}
\hline & $\begin{array}{l}\text { Spearman R } \\
\text { coefficient }\end{array}$ & $\mathrm{p}$ & $\begin{array}{l}\text { Pearson R (after } \\
\text { logarithmic } \\
\text { transformation) }\end{array}$ & $\mathrm{p}$ \\
\hline Patient group & -0.002 & 0.987 & 0.005 & 0.962 \\
\hline With AF & 0.013 & 0.934 & 0.013 & 0.934 \\
\hline Sinus rhythm & -0.03 & 0.848 & -0.03 & 0.848 \\
\hline
\end{tabular}

Table 3

THE RELATIONSHIP BETWEEN LEPTIN AND MR-PrOANP DEPENDING ON THE PRESENCE OF ATRIAL FIBRILLATION

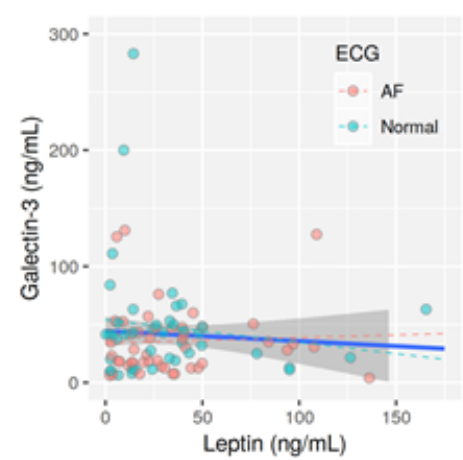

for the diagnosis and treatment of heart failure, detection of BNP values lower than $100 \mathrm{pg} / \mathrm{mL}$, NT-proBNP values lower than $125 \mathrm{pg} / \mathrm{mL}$ and MR-proANP values lower than $120 \mathrm{pmol} / \mathrm{L}$ excludes the diagnosis of heart failure [1]. However, the positive predictive value of these markers is reduced [1]. In order to improve this positive predictive value, The American Heart Association has recently proposed differentNT-proBNP cut-off values depending on age: $450 \mathrm{pg} / \mathrm{mL}$ for patients aged <50 years, $900 \mathrm{pg} / \mathrm{mL}$ for those aged between 50 and 75 years, and $1800 \mathrm{pg} / \mathrm{mL}$ for patients aged $>75$ years, as well as a BNP value $>400$ $\mathrm{pg} / \mathrm{mL}$ [2]. Natriuretic peptides remain the gold standard of heartfailure biomarkers. ANP and BNP are produced in the atria and ventricles, respectively, in response to volume or pressure overload in heart failure. The biological functions of ANP and BNP include different compensatory mechanisms, such as stimulation of natriuresis, diuresis, vasodilation. Also, in addition to their diagnostic role, they have an extremely important prognostic role; studies have demonstrated a linear relationship between their serum concentrations and cardiovascular mortality [2]. Doust et al. showed that an increase in BNP values by $100 \mathrm{pg} / \mathrm{mL}$ is associated with a $35 \%$ higher relative risk of death [8]. However, there are some important limitations that should be taken into account when interpreting natriuretic peptide values. Obese patients with heart failure frequently have lower values of cardiac natriuretic peptides [1, 2]; an inverse linear relationship between BMI and natriuretic peptide values was described, as we also demonstrated in previous studies $[2,9,10]$. Regarding atrial fibrillation, NTproBNP values are increased in patients with this comorbidity, proving potentially useful in stratifying risk, 


\begin{tabular}{|l|l|l|l|l|}
\hline & Spearman R & $\mathrm{p}$ & $\begin{array}{l}\text { Pearson R (after } \\
\text { logarithmic } \\
\text { transformation) }\end{array}$ & $\mathrm{p}$ \\
\hline All patients & 0.027 & 0.805 & -0.003 & 0.977 \\
\hline AF & 0.052 & 0.73 & 0.052 & 0.73 \\
\hline Sinus rhythm & 0.022 & 0.889 & 0.022 & 0.889 \\
\hline
\end{tabular}

Table 4

THE RELATIONSHIP BETWEEN LEPTIN AND GALECTIN-3 DEPENDING ON THE PRESENCE OF ATRIAL FIBRILLATION defining prognosis and even making therapeutic decision $[1,11]$. Nevertheless, NT-proBNP values decrease in the presence of obesity in patients with atrial fibrillation [12]. In the current study, NT-proBNP is the only biomarker that showed a statistically significant inverse relationship with left ventricular ejection fraction. Therefore, although NTproBNP has significantly lower values in obese patients with heart failure compared to the general population, it maintains its prognostic value. However, unlike the other studied biomarkers, only NT-proBNP concentrations were strongly influenced by the presence of renal dysfunction.

ANP prohormone, composed of 126 amino acids, known as proANP, has a longer half-life than that of ANP, its serum measurement being more reliable. In this context, MRproANP is a promising new biomarker of heart failure, which has proven its non-inferiority to BNP in clinical practice in the diagnosis of acute heart failure, improving at the same time the diagnosis of patients with BNP values in the gray area (between 100 and $500 \mathrm{pg} / \mathrm{mL}$ ) and obese patients [3]. Determining NT-proBNP and MR-proANP increases diagnostic accuracy among these patients. In the current study, the median value of MR-proANP was $246 \mathrm{pmol} / \mathrm{L}$, significantly increased compared to the cutoff value of $120 \mathrm{pmol} / \mathrm{L}$ proposed by current guidelines [1]. Unlike NT-proBNP, this was not correlated with BMI in the studied group of overweight and obese patients. Studies have demonstrated that patients with atrial fibrillation have increased values of MR-proANP, its determination also being useful in identifying persons athigh risk for developing atrial fibrillation [13]. The current study did not find higher NT-proBNP or MR-proANP values in overweight or obese patients with heart failure and AF compared to values recorded in heart failure patients with sinus rhythm; these results are similar to those of the $\mathrm{BACH}$ trial [14]. Obese patients most frequently develop heart failure with preserved ejection fraction. The new biomarkers of heart failure (cardiac troponins, MR-pro-adrenomedullin, cystatin C, interleukin-6, galectin-3, ST2) are extremely important for improving diagnostic accuracy, explaining the pathophysiological mechanisms involved, as well as for developing new therapies [2]. Galectin-3 is a $30 \mathrm{kDa}$ protein that contains a carbohydrate binding domain of 130 amino acids allowing specific beta-galactosidase binding, and is coded by a single gene, LGALS3, located on chromosome 14 q21-q22 [15]. Studies have demonstrated its implication in the development and progression of heart failure by stimulating myofibroblast proliferation, fibrogenesis, inflammation, with considerable impact on ventricular remodeling [15]. Recently, galectin-3 concentrations were proven to have an important prognostic value in patients with $\mathrm{HF}$, their increase being independently associated with an elevated risk of all-cause mortality and with the rate of readmissions for decompensated heart failure [15-18]. In the present study, 66 (75\%) of patients had increased Gal3 values ( $>17.8 \mathrm{ng} / \mathrm{mL}$ ). Experimental research has shown that inhibition of galectin-3 with specific carbohydrates is associated with improved diastolic dysfunction, through a decrease in left ventricular telediastolic pressure and an improvement in left ventricular relaxation, which are accompanied by a quasi-complete inhibition of myocardial fibrosis. There is clear evidence that galectin-3 is increased in obese patients, suggesting a possible pathophysiological mechanism in the development of heartfailure, particularly with preserved ejection fraction [19]. However, it is notyet fully understood whether galectin-3 in increased concentrations can stimulate adipose tissue proliferation and if galectin-3, obesity and heart failure are associated through the pro-inflammatory effects of excess adipose tissue. In the current study, the mean value of galectin-3 was increased (34 ng/mL), but there was no statistically significant increase with the increase in BMI. At the same time, renal function assessed by the glomerular filtration rate did not significantly influence galectin-3 values. In this regard, some studies have demonstrated the diagnostic accuracy of galectin-3 in heart failure irrespective of the renal function [19], while other findings demonstrate a diminished prognostic accuracy of Gal-3 in patients with heart failure and renal disease [16].

Leptin is a proatherogenic adipokine, which is excessively secreted in obese patients, together with other adipokines with similar effects, such as resisitin [20] or visfatin [21]. Overweight and obese patients with heart failure are hyperleptinemic. Chronic hyperleptinemia, through generation of reactive oxygen species (ROS), can be involved in the progression of atherosclerotic disease, but can also be a marker of heart failure progression in patients at high risk, by both central and peripheral stimulation of the sympathetic nervous system [22]. At the same time, other studies provide clear evidence that hyperleptinemia found in obese patients is associated with a favorable prognosis of heart failure by neutralizing the harmful effects of other pro-inflammatory cytokines on the myocardium [18].

\section{Conclusions}

In the current study we demonstrated that there is no statistically significant direct relationship between serum leptin concentrations and the levels of the studied HF markers (NT-proBNP, MR-proANP, Gal-3). So, the role of leptin as an independent predictor of heart failure prognosis in overweight and obese patients remains questionable. Certainly, when interpreting the results of this study, the reduced number of patients and the presence of other comorbidities thatmight have influenced the results should be taken into account. In conclusion, obese patients with heart failure had significantly increased values of all the studied parameters (NT-proBNP, MR-proANP, Gal-3, leptin), but the presence of atrial fibrillation did not influence their levels. At the same time, high leptin levels were not directly correlated with the levels of heart failure-specific biomarkers.

Aknowledgement: The study was supported by the institutional research grant "I luliu Hatieganu" University of Medicine and Pharmacy, Cluj-Napoca, Romania (PCD 2016- No. 7690/39/15.04.2016).

\section{References}

1.PONIKOWSKI, P.1., VOORS, A.A., ANKER, S.D., BUENO, H., CLELAND, J.G., COATS, A.J . et al. Eur Heart J ., 37, nr.27, 2016, p.2129-2200.

2.CHOW, S.L., MAISEL, A.S., ANAND, I., BOZKURT, B., DE BOER, R.A., FELKER, G.M., et al. Circulation, 135, nr. 22, 2017, p.e1054-e1091. 
3.YANCY, C.W., JESSUP, M., BOZKURT, B., BUTLER, J., CASEY DE, J.R., COLVIN, M.M., et al. J Card Fail., 8, 2017, p.628-651.

4.RUSTAMOVA, Y., DOBREANU, D. Revista Românã de Medicinã de Laborator, 26, 2018, p.267-270.

5.GARG, A., VIRMANI, D., AGRAWAL, S., AGARWAL, C., SHARMA, A., STEFANINI, G., KOSTIS, J.B. Cardiology., 136, nr. 3, 2017, p.192-203.

6.WANNAMETHEE, S.G., SHAPER, A.G., WHINCUP, P.H., LENNON, L., SATTAR, N. J Am Coll Cardiol., 58, nr. 18, 2011, p.1870-1877.

7.FONAROW, G.C., CLARK, A.L. Prog Cardiovasc Dis., 61, nr. 2, 2018, p.151-156.

8.DOUST, J .A, PIETRZAK, E., DOBSON, A., GLASZIOU, P. BMJ ., 330, nr. 7492, 2005, p.625.

9.DADARLAT, A., SITAR-TAUT, A.V., ZDRENGHEA, D., POP, D., BUZOIANU A. Balneo Research J ournal., 9, nr. 1, 2018, p.28-33.

10.AURSULESEI, V., MANTA, A., AL NAMAT, R., HUGIANU, M., MOLOCE, A.M., AURSULESEI V., C., CONSTANTIN, M. REV.CHIM.(Bucharest), 69, no. 7, 2018, p. 1673-1677

11.RICHARDS, M., DI SOMMA, S., MUELLER, C., NOWAK, R., PEACOCK, W.F., PONIKOWSKI, P. et al. JACC Heart Fail., 1, nr. 3, 2013, p.192-199. 12.ZHENG, L.H., WU, L.M., YAO, Y., CHEN, W.S., BAO, J.R., HUANG, W., et al. PLoS One., 9, nr. 8, 2014, p.e105249.

13.BERNTSSON, J., SMITH, J.G., NILSSON, P.M., HEDBLAD, B., MELANDER, O., ENGSTROM, G. Eur J Prev Cardiol., 24, nr. 8, 2017, p. 788-795.
14.MAISEL, A., MUELLER, C., NOWAK, R., PEACOCK, W.F, LANDSBERG, J.W, PONIKOWSKI, P., et al. J Am Coll Cardiol., 55, 2010, p.2062-2076. 15.DE BOER, R.A., EDELMANN, F., COHEN-SOLAL, A., MAMAS, M.A., MAISEL, A., PIESKE, B. Eur J Heart Fail., 15, nr. 10, 2013, p.1095-1101. 16.GEHLKEN, C., SUTHAHAR, N., MEIJ ERS, W.C., DE BOER, RA. Heart Fail Clin., 14, nr. 1, 2018, p.75-92.

17.FRENCH, B., WANG, L., KY, B., et al. J Card Fail., 22, nr. 4, 2016; p.256-262.

18.VAN DER VELDE, A.R., GULLESTAD, L., UELAND, T., et al. Circ Heart Fail., 6, nr. 2, 2013, p.219-226.

19.MENINI,S., IACOBINI, C., BLASETTI FANTAUZZI, C., PESCE, C.M., PUGLIESE., G. 2016, article ID 9618092.

20.FARCAS, A.,D., RUSU, A., STOIA, M., A., VIDA-SIMITI, L.,A. Cytokine, 103, 2018, p.46-49

21.MOCAN HOGNOGI, L.D., MOCAN HOGNOGI, R.F., MALUTAN, A, FARCAS, A.D. VIDA SIMITI, L. Rev. Chim.(Bucharest), 2017, 68, no. 9, p.2108-2111.

22.SZABO, T., SCHERBAKOV, N., SANDEK, A., KUNG, T., VON HAEHLING, S., LAINSCAK, M., et al. Nutr Metab Cardiovasc Dis., 24, nr. 1, 2014, p.50-56.

$\overline{\text { Manuscript received: } 20.02 .2019}$ 